\title{
Design and Performance Evaluation of a Multi-Temperature Flat Plate Solar Collector
}

\author{
Selfa Johnson Zwalnana ${ }^{*}$, Gideon Ayuba Duvuna ${ }^{b}$, Yousif Abdalla Abakra, \\ Tiyamike Banda ${ }^{a}$
}

${ }^{a}$ Department of Mechanical Material and Manufacturing Engineering, University of Nottingham, Malaysia

${ }^{b}$ Department of Mechanical Engineering, Federal Polytechnic Mubi, Adamawa State, Nigeria

\begin{abstract}
The standard flat-plate solar collector utilises a single copper tube to remove the absorber plate's heat. This type of collector's primary purpose is to provide hot water for a single application. Hot water can be required for different applications at different temperatures. Besides, using the standard collector's configuration may increase thermal demand and increase the collector's size. Therefore, this study proposes a novel solar water heating configuration that uses three in-line fluid passages. The goal is to design a single collector that provides hot water for various uses: Sterilisation, washing, and postnatal care. Thus, the proposed system was modelled, and a numerical simulation conducted. This analysis compares the proposed system's output and the standard collector's output. The results showed that the thermal load demand was reduced by $27 \%$ when the hot water demand for these services was generated using three separate tanks. The serpentine collector's efficiency with three fluid passages is increased by $20 \%$ compared to the traditional serpentine collector. The thermal energy delivered to meet load was $30 \%$ higher than that of the traditional serpentine system. The experimental and simulated system performance is in near agreement with an average percentage error $\mathrm{Cv}(\mathrm{RMSE})$ of $8.75 \%$ and confidence level NSE of about $87 \%$. Since the proposed serpentine collector has a higher overall thermal production, it is recommended for use with hot water, which has to be heated to different temperatures.
\end{abstract}

Keywords: : Solar water heater, Serpentine collector, Simulation, Collector efficiency, Solar fraction

Article History: Received: 30th Sept 2020; Revised: 27th January 2021; Accepted: 25 ${ }^{\text {th }}$ February 2021; Available online: $12^{\text {th }}$ March 2021

How to Cite This Article: Zwalnan, S.J., Dayuna, G.A., Abakr, Y.A, and Banda, T. (2021) Design and Performance Evaluation of a Multitemperature Flat Plate Solar Collector. International Journal of Renewable Energy Development, 10(3), 537-549 https://doi.org/10.14710/ijred.2021.33213

\section{Introduction}

Solar energy is the best gift to humanity and the world's most abundant renewable and cheapest energy source. The estimated power from the sun intercepted by the earth is approximately $1.8 \times 10^{11} \mathrm{MW}$ daily, which are thousands of times larger than the world energy consumption rate of all commercial energy resources (Sukhatme, 2009). A good guess puts the annual energy receives on the earth at about $2,895,000 \mathrm{EJ}$ annually, which is greater than total non-renewable energy sources of about 325,399 EJ (World Energy Council, 2004). Thus, in principle, solar energy could supply all the present and future energy needs of the world continuingly if only $10 \%$ of the solar energy can be harvested (Memon et al., 2020). The solar thermal energy system is a viable energy alternative which can reduce hot water demand in health centres and cottage industries (Olatomiwa, 2016; Olatomiwa, Mekhilef and Ohunakin, 2016; Ohijeagbon et $a l ., 2019)$. Even though solar energy holds the potential to transition to low carbon energy sources, many are still required to promote adaptability in many locations. Madvar et al. (2018) discuss essential energy policy and security issue based on the Iranian scenario that will accelerate the deployment and installation of renewable energy systems. Solar water heating systems have shown in many ways to reduce hot water energy consumption significantly. One primary concern that has attracted much research is the solar water heaters' low energy conversion efficiency (Deng et al., 2019; Eltaweel, AbdelRehim and Hussien, 2020).

Consequently, many studies have been carried out to improve solar energy system efficiency. Dang et al. (2019) estimated a thermosyphon solar water heater's thermal efficiency based on the storage tank heat exchanger's traditional and twisted style. From the result, the system's collector efficiency based on the "twisted heat exchanger" configuration was about $12.8 \%$ greater than that of the "conventional round heat exchanger." Rejeb et al. (2020) developed and tested a new PVT collector's performance, designed using a low emissivity coating with an optical anti-reflective content. A multi-physics model

\footnotetext{
* Corresponding author: youremail@mail.com
} 
was developed to evaluate the electrical and thermal performance of the new design. The results showed a higher electrical and thermal efficiency of $15.4 \%$ and $73 \%$ respectively for the proposed PVT, compared with the basic PVT which has $13.7 \%$ and $58 \%$ electrical and thermal efficiencies respectively. Shariah and Shialabi (2013) have used the TRNSYS simulation program to optimise a solar flat plate water heater under Jordan's environment. The results indicate that the solar fraction of the energy system can be improved by 10 to $25 \%$ if the components are correctly measured and parameters are optimally selected.

Sohani et al. (2020) through outdoor experiment under Iran's weather condition evaluated the conventional solar-still thermal performance based on eight different system configurations. In the analysis of their result, the authors found that employing both the side mirror and sun-tracking on a solar-still operated in a passive mode increase the daily water production by about $43.1 \%$ relative to the conventional solar still. Moreover, Hoseinzadeh et al.(2017) discovered that employing the flat plate solar collectors for cooling and heating of traditional households in Northern Iran is not currently competitive with the conventional energy system. Nezhade, (2017) found that high input of auxiliary heating in a solar water heater design for an aviculture unit, would cause the inlet and outlet of the heat exchanger to be equal for a much longer time and thus reduce the heat exchanger efficiency. Hoseinzadeh et al. (2020) used the HOMER software to find the optimal size of the solar photovoltaic required to be combined with a $65 \mathrm{~kW}$ capacity hydroelectric power system in order to improve the system's year-round capacity in meeting the power requirement a remote village of Mashhad Sarrood far from the grid in Iran.

Several literature works have reported attempts to redirect fluid flow over the heated surface to enhance the heat transfer between the surface and the fluid. A recent study (Menni, Azzi and Chamkha, 2019) showed that the heat transfer coefficient on a heated surface substantially influences the heat transfer between the heated surface and the fluid. Ahmadi et al. (2018) reviewed the current solar energy technologies to find the technology that best matches power production. The review concluded that the direct method of converting solar energy to power employing the PV module is most appropriate in scale power production. In contrast, employing a solar concentrator to generate steam, which is converted to power, is beneficial with a higher return in large-scale power production. Fawaz, Badawy, Abd Rabbo, \& Elfeky (2018) investigated employing numerical simulation, the V-baffles' effect with 45 degrees angle of attack mounted with an in-line arrangement in a square channel with a fully developed turbulent fluid. Their findings showed that an in-line V-baffle design in fluid channels leads to more uniform mixing with high thermal enhancement, especially for flows at Reynolds numbers under 5000. In a recent study, Ahmadi et al. (2020) employed machine learning techniques to predict the thermal energy production and collector efficiency of a PVT collector. The statistical model prediction of the PVT collector efficiency shows a high confidence level $\left(\mathrm{R}^{2}\right)$ of 0.986 and minimum Mean Squared Error (MSE) of 0.007.
Zulkifle et al. (2018) found that the thermal efficiency (71.18\%) of a Fresnel covered air heater is higher than that of a glass-covered air heater (54.10\%). Furthermore, the authors' outdoor test under the Bangi (Malaysia) weather revealed that the Fresnel covered V-groove air heater delivered hot air at $38.39^{\circ} \mathrm{C}$. In contrast, the glasscovered V-groove air heated delivered hot air at $35.8^{\circ} \mathrm{C}$. Hossain et al.(2016) modified the serpentine flow pattern, to a two-side parallel serpentine flow pattern to increase the collector's thermal efficiency. The performance of the collector was experimentally tested under an outdoor condition in June and July. The result shows that the 2sides parallel serpentine with bends at $90^{\circ}$ has a peak collector efficiency of $81.26 \%$ and $80.10 \%$ for June and July. Deng et al.(2019) submitted based on China's economic scenario that the use of anti-freeze fluid solution in the indirect-loop employing refrigerant in the primary heating circuit of the flat plate solar collector for extremely low-temperature region potentially increases the system's cost by about $30 \%$ compared to an direct-loop system of heating water. To avoid structural failure, in the directloop solar water heating system due to freezing, the authors developed a new flat plate collector that is iceimmuned using a flexible and compressible silicone tube. Besides, the system's primary heating circuit operates in an open loop eliminating the need for a heat exchanger. The outdoor experimental test results showed that the header riser type collector's performance based on the flexible and compressible tubing performs slightly better than the serpentine tube panel. However, the serpentine tube panel's optical loss is lower by about $3.4-3.9 \%$ than that of the header riser type.

In addition to the structural improvement in the flat plate collector design, many attempts have been made to improve the collector's efficiency by using different work fluids (Kiliç, Menlik and Sözen, 2018; Eltaweel, AbdelRehim and Hussien, 2020). The serpentine solar collector's basic structure comprises a single line copper tubing embedded on an absorber plate in a serpentine fashion inside a casing cover at the top utilising glass. Many studies have suggested different structural modifications to the copper tubing with excellent thermal efficiency improvement compared to the primary serpentine tubing (Rosli et al., 2014).

For most flat plate collector design, the collector is designed with a single fluid passage to deliver the desired hot water through one outlet. This type of collector design is mostly suitable for hot water application with a fixed desired temperature. However, in health centres, there is variation in the desired hot water's temperature based on application. For example, hot water requirements for equipment sterilisation are usually needed at a temperature of 55 to $60^{\circ} \mathrm{C}$ (Backer, 1996; Costa and Bracco, 2009). For laundry purposes, hot water temperatures are requested at 45 to $54^{\circ} \mathrm{C}$ (Honisch, Stamminger and Bockmühl, 2014). According to Murphy (1993), and Lima et al. (2015), the hot water for bathing (postnatal service) is usually delivered at a temperature of around 37 to $45^{\circ} \mathrm{C}$.

Therefore, this research proposes a serpentine collector configuration with three separate fluid passages to deliver hot water at three different temperatures to meet hot water demand for sterilisation at $60^{\circ} \mathrm{C}$, laundry at $54^{\circ} \mathrm{C}$ and bathing purpose at $43^{\circ} \mathrm{C}$ for application in 
small health centres. Therefore, the goal is to compare the benefit of the proposed configuration over the conventional flat plate collector used in most studies. The remaining sections are structured as follows: Section 2 discusses the proposed system architecture, system sizing and performance evaluation methodology. Section 3 explains the results obtained, while section 4 summarises the finding and conclusion of this study

\section{Materials and Methods}

\subsection{Description of collector and system}

The conventional serpentine solar collector is modified to have three different in-line copper pipes fluid passages, as shown in Figure 1. The hot water requirement of 150 $\mathrm{L} /$ day at a temperature of $54^{\circ} \mathrm{C}$ for laundry in 'tank 1 ' is conveyed by the first pump (P1) through the black passageway to reach the collector through the first inlet. Similarly, the water requirement of $88 \mathrm{~L} /$ day at $60^{\circ} \mathrm{C}$ for sterilisation and postnatal services of $113 \mathrm{~L} /$ day at $43^{\circ} \mathrm{C}$ in tank 2 and 3 enter the collector through the second (blue passages) and third (red passages) inlets respectively. Since water from the different tanks is conveyed via different fluid passages in the collector and each travelling the different copper tubing length, the water exits the collector at different temperatures. The tanks are sized based on each application's hot water demand, as shown in Table 1. Furthermore, the power needed to operate the constant flow pumps is obtained from a 200 Watts PV module installed as part of the system. The system's analysis is based on 80 Litre per bed hot water specifications as recommended by (Fuentes, Arce and Salom, 2018) for three applications: laundry, sterilisation and postnatal services for a four-bed outpatient rural clinic located in Bauchi Nigeria.

\subsection{Methodology for collector sizing}

The sensible heat consideration in system design is calculated as the heat required to increase the temperature to meet the desired load temperature. For instance, if the rate of hot water demand is $\dot{m}_{L}$, in $\mathrm{kg} / \mathrm{hr}$ then the heat $Q_{s}$ required per day to increase the mains water temperature (Tmains) to the desired load temperature (TL) is expressed in Eq. (1) (Hoseinzadeh and Azadi, 2017);

$$
Q_{s}=\int_{1}^{24} \dot{m}_{L} C_{p}\left(T_{L}-T_{\text {mains }}\right)
$$

Losses from the storage tanks may be significant and should be considered part of the total system load. The rate of tank losses $\left(Q_{s t L}\right)$ is estimated using the tank loss coefficient-area product $(U A)_{s t}$ (mostly specified in the manufactures datasheet and the temperature difference between the tank water temperature $T_{\text {st }}$ and the ambient temperature $T_{a}$ surrounding the tank. Similarly, the total loss per day is calculated using Eq (2) (Govind and Shireesh, 2006).

$$
Q_{s t L}=\int_{1}^{24}(U A)_{s t}\left(T_{s t}-T_{a}\right) d t
$$

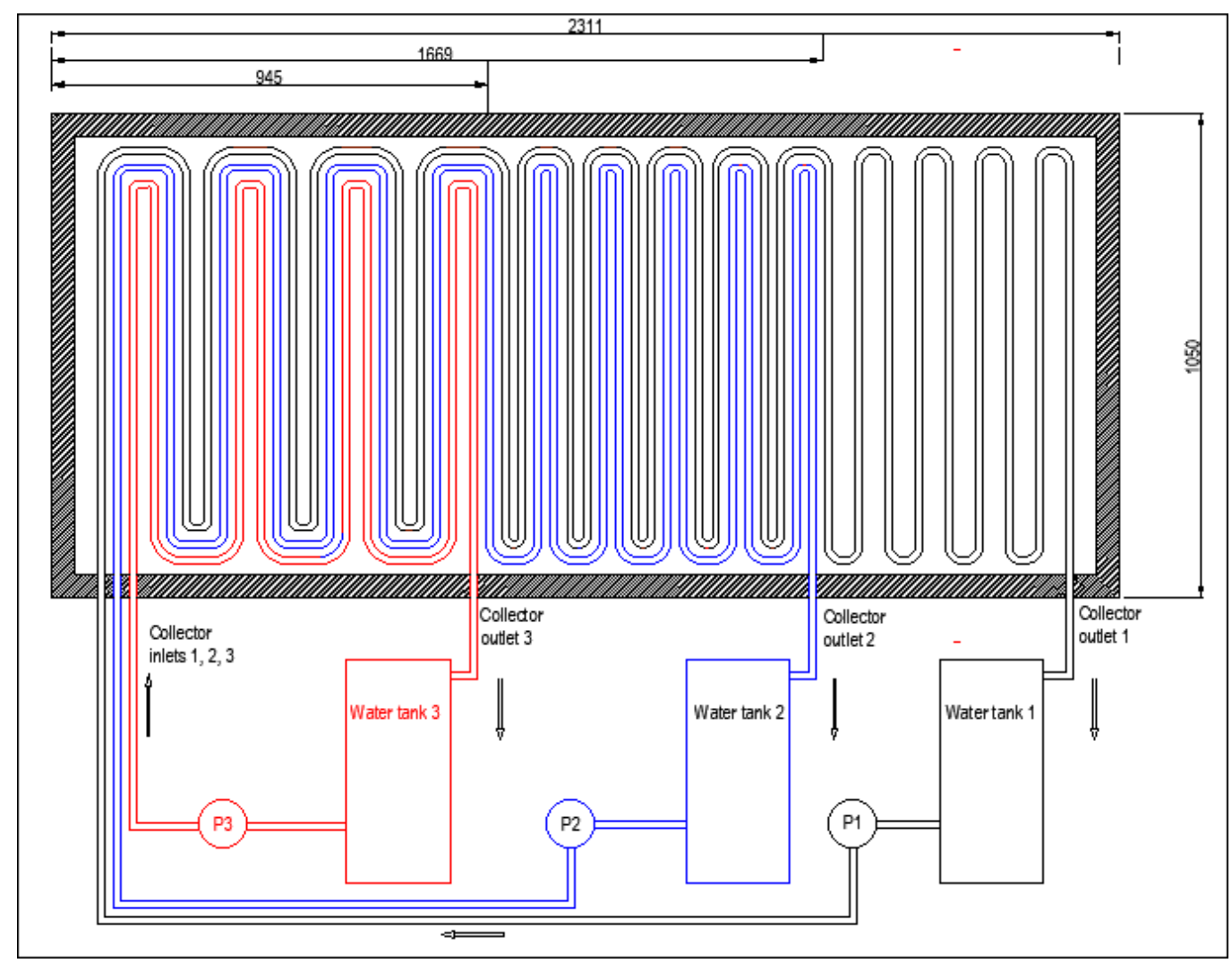

Fig 1. Schematic of the tri-inlet serpentine solar water heating system 
For good performance, the solar collector must be sized to meet both the sensible heat requirement and the tank loss which is expressed by Eq (3);

$$
Q_{L}=Q_{s}+Q_{s t L}
$$

The heat needed to raise the temperature of water required at a flow rate $(\dot{m})$ in $\mathrm{kg} / \mathrm{hr}$ of the supply mains temperature $\left(T_{\text {mains }}\right)$ to the load desire temperature for laundry, postnatal and sterilisation applications is calculated using $\mathrm{Eq}(4)$ to (6) respectively.

$$
\begin{aligned}
& Q_{l}=\int_{1}^{24}\left(\dot{m} C_{p}\left(T_{l}-T_{\text {main }}\right)+Q_{s t L}\right) d t \\
& Q_{p}=\int_{1}^{24}\left(\dot{m} C_{p}\left(T_{p}-T_{\text {main }}\right)+Q_{s t p}\right) d t \\
& Q_{s}=\int_{1}^{24}\left(\dot{m} C_{p}\left(T_{s}-T_{\text {main }}\right)+Q_{s t s}\right) d t
\end{aligned}
$$

where $C_{p}$ is the specific heat capacity of water in $\mathrm{kJ} / \mathrm{kg} . \mathrm{K}$. $Q_{l}, Q_{p}$, and $Q_{s}$ are the average daily thermal energy demand for laundry, postnatal and sterilisation services obtained by integrating the hourly hot water demands. $T_{L}$, $T_{p}$ and $T_{s}$ are the desired hot water temperature for the laundry, postnatal and sterilisation services. The second term in Eqs. (4) to (6) represents the tank losses of the respective hot water storage tanks for the various applications.

Furthermore, from each application's daily thermal energy requirement values, the collector area requirement is approximated for each application based on Eq. (7) to Eq (9).

$$
A_{l}=\frac{Q_{l}}{L F \times \int_{1}^{24}\left(I_{T}\right) d t}
$$

$$
\begin{aligned}
& A_{p}=\frac{Q_{p}}{L F \times \int_{1}^{24}\left(I_{T}\right) d t} \\
& A_{S}=\frac{Q_{S}}{L F \times \int_{1}^{24}\left(I_{T}\right) d t}
\end{aligned}
$$

where LF (0.56) is the hourly utilizability factor of the hourly available irradiance $\left(I_{T}\right)$ obtained from the study location's solar radiation analysis based on formulations, as suggested by Duffie and Beckman (2013).

Notably, estimating each application's collector area is not for the three collectors to be constructed separately. The goal is to have an idea of the highest collector area needed per application. Consequently, the smaller areas are embedded in the biggest area to form a single collector, as shown in Figure 1. The size of each collector area estimated based on Eqs (7) to (9) determines the length water passages' tubing, as shown in Figure (1). The application with the highest estimated collector area has the most extended collector tubing, as indicated by the black colour tubing in Figure 1. Accordingly, the length of the fluid passage for each application is per the collector area.

\subsection{Modelling and Performance simulation}

To simulate the proposed solar water heating system's annual performance, the entire energy system model was formulated in the TRNSYS simulation studio, as shown in Figure 2. In the simulation studio, each component of the entire system is represented by a blackbox model (called TYPE) of the component found in the component library of the studio. Besides, each TYPE of the system's component models the component behaviour based on mathematical equations described in the TRNSYS documentation.

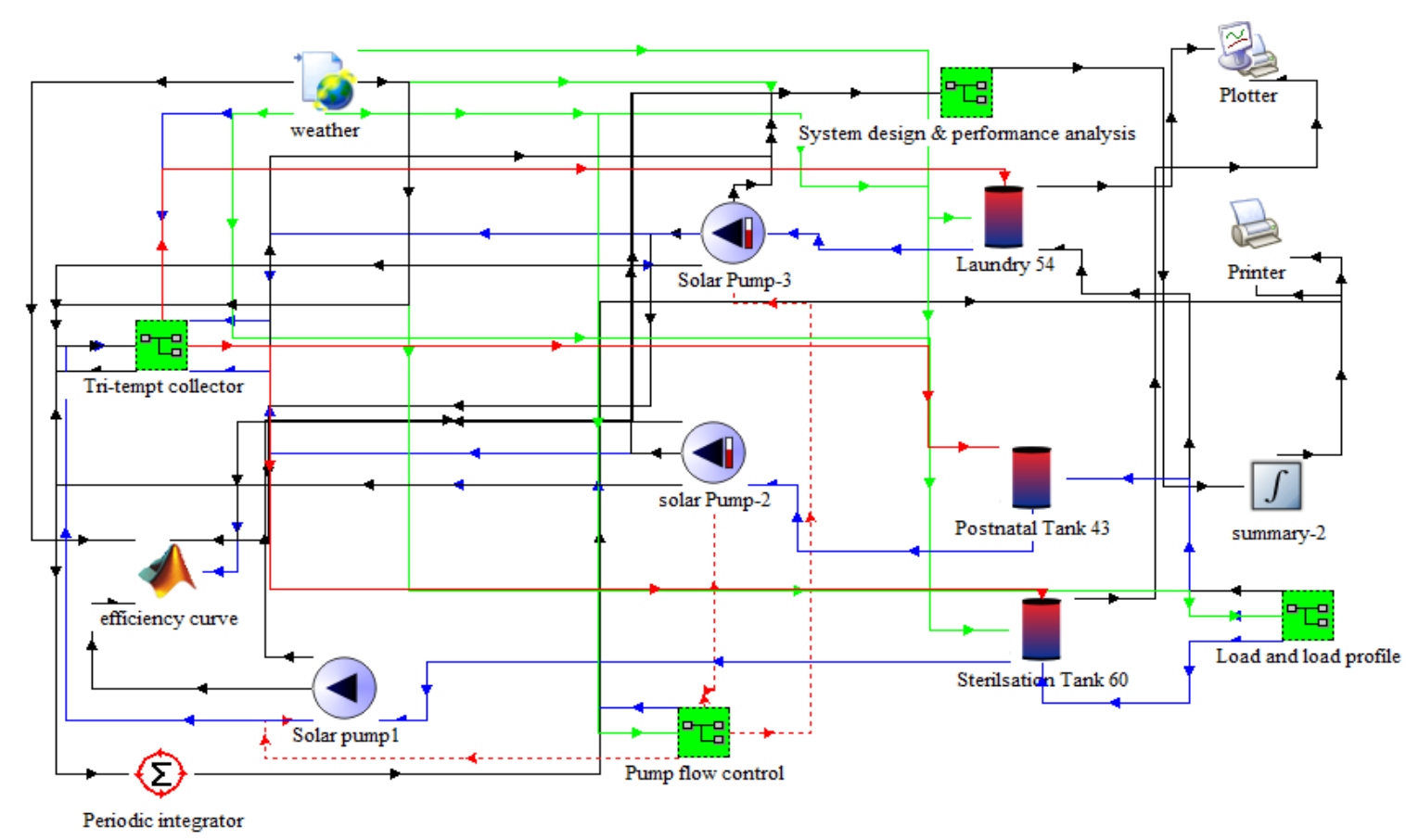

Fig 2. TRNSYS model of the proposed energy system developed 


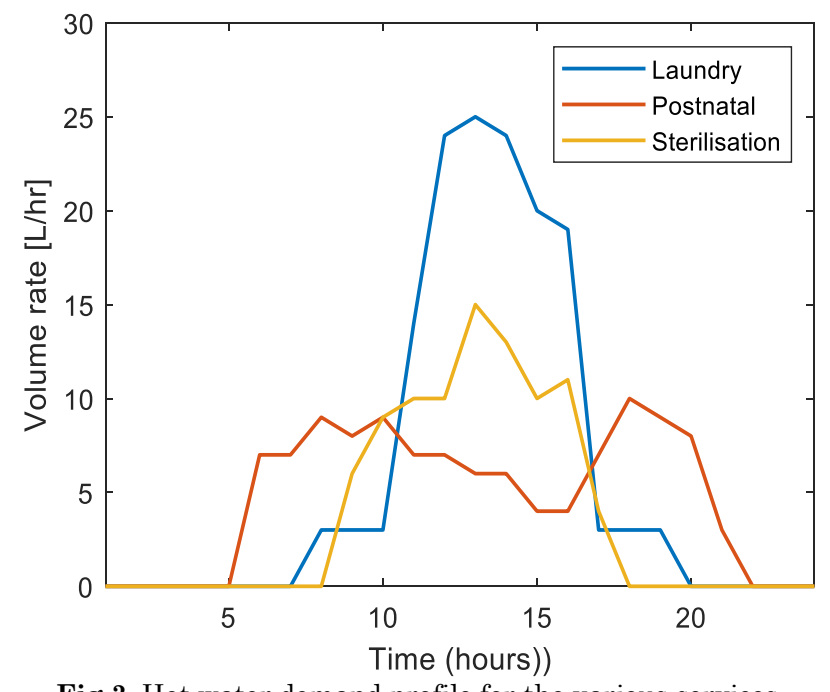

Fig 3. Hot water demand profile for the various services

Accordingly, each TYPE takes input from other components and outputs the component performance based on its inputs. Notably, the components (TYPES) of the entire energy system must be connected in a manner that depicts the correct interactions between each system component. Furthermore, to customise any component's input based on the designers' choice, the equation block is used. In this block, the component control operation can be formulated based on some input equations. For instance, the "equation blocks" in Figure 2 shown by the green box represent the proposed pump control and the system's performance analysis, as indicated by each block's name. In this study, the pump is controlled to run at a constant flow rate of $0.02 \mathrm{~kg} / \mathrm{s}$ only when solar radiation is available.

Moreover, the general utility forcing function called TYPE 14 is used to set a time-dependent hot water demand profile, as depicted in Figure 2 with the green box. Two load profiles are adopted. The first with a peak water demand around midday usually for sterilisation and laundry operation and the second with early and late evening peak for the postnatal services as shown in Figure 3. According to a study conducted by Bujak, these profiles are typical load profiles of health centres (Bujak, 2010). After each part of the entire system's parameters are defined based on careful engineering design principles, as shown in Table 1, the system's annual performance is simulated under the actual load and outdoor weather conditions of the health centre located in Bauchi, Nigeria.

The system's efficiency was compared with the typical serpentine solar heating system, as seen in Figure 4. The typical serpentine has the same dimensions and parameters as the proposed system. The comparison aims to benchmark the proposed solar water heating system with the typical serpentine configuration. In this case, this traditional serpentine solar heating system is utilised to meet the thermal demand of the same health centre based on single hot water tank with a volume equal to the total volume of hot water demand for the three applications as in generality of much-published work with a single centralised storage tank was used for this collective application (Lima et al., 2015; Fertahi et al., 2019; Li et al., 2020).

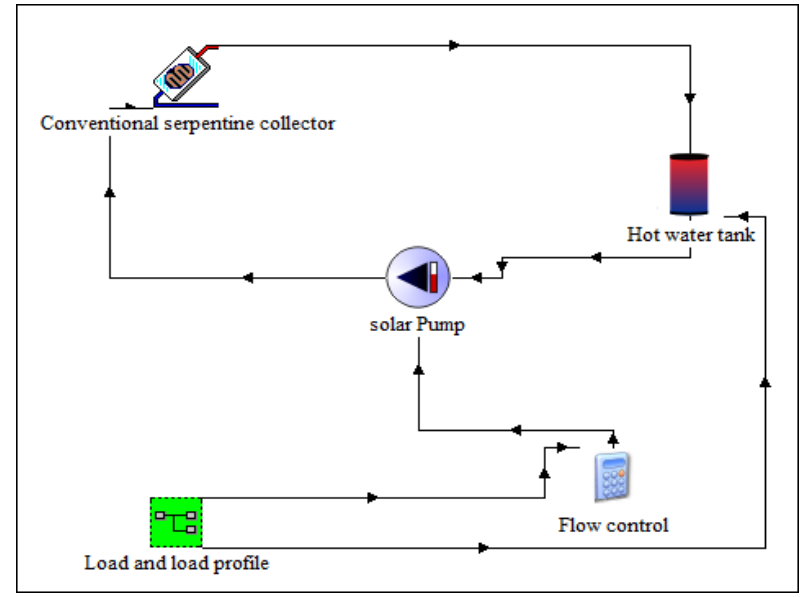

Fig 4. Model of the conventional serpentine water heating developed using TRNSYS

Consequently, the monthly average daily system performance is evaluated based on the sets of equations described in section 2.4. The results of the annual performance assessment are discussed in the next sections

\subsection{System Performance measurement and analysis}

In solar systems design, the weather conditions strongly influence the size of the system. However, the weather condition of any place is highly random and unpredictable. Therefore, proper sizing of the solar system is a complicated and tricky task (Kalogirou, 2009). The numerical simulation using TRNSYS is an approach used to evaluate the solar system's long term (annual) performance based on the preliminary design parameters (Diez et al., 2019). With this approach, it is possible to visualise the hourly and even daily performance throughout the year. Therefore, it will be possible to adjust design parameters until a reliable performance is reached. To predict the thermal characteristic in a steady-state of the flat plate collector, the Hottel-Whillier-Bliss (HWB) mathematical models and energy balance equations expressed in Eq.(10) models the collector component. The rate of useful energy gain of the solar collector at a given moment is the positive difference between the energy absorbed by the plate and the energy lost by the collector to the environment as described by Eq. (10) (Diez et al., 2019).

$$
\dot{Q_{u}}=F_{R}\left[S-U_{L}\left(T_{i}-T_{a}\right)\right]^{+}
$$

Where $\mathrm{S}, \mathrm{U}_{\mathrm{L}}, \mathrm{T}_{\mathrm{i}}$ and $\mathrm{T}_{\mathrm{a}}$ are the energy absorbed by the absorber plate, the collector overall heat loss coefficient, circulating fluid collector inlet temperature and the temperature of the surrounding where the collector is placed respectively. The plus superscript indicates that only positive values of the square bracket terms are to be used. The Hottel-Whillier equation defines the efficiency of a solar collector under a steady radiant energy per unit area $\left(I_{T}\right)$ falling on the collector surface with fluid flowing at a steady fluid flow rate, and constant wind speed and ambient temperature, as expressed in Eqn. (11) (Braun et al. 2020) 


$$
\eta_{\text {coll }}=\frac{Q_{u}}{I_{T} A_{c}}
$$

The collector efficiency is calculated as the ratio of the total useful energy from the collector to the total solar radiation $\left(I_{T} A_{c}\right)$ received on the collector surface. The efficiency is estimated from Eq. (12)

$\eta_{\text {coll }}=\frac{Q_{u 1}+Q_{u 2}+Q_{u 3}}{I_{T} A_{c}}$

where $\mathrm{Qu}_{1}, \mathrm{Qu}_{2}$ and $\mathrm{Qu}_{3}$ are the useful energy of the proposed collector from outlet 1, 2 and 3 respectively and Ac is the total collector area.

To evaluate the overall system performance, the solar fraction $\mathrm{SF}$ is a better performance indicator than the collector efficiency and heat removal factor. It assesses the entire system's overall efficiency rather than a component. Beausoleil-Morrison et al. (2019) expressed solar fraction as the fraction of the actual hot water demand met by the solar system to the total system load.

$S F=\frac{\text { Actual load met by solar system }}{\text { Total system load }}=1-\frac{Q_{A u x}}{Q_{L}}$

where, $Q_{\text {Aux }}$ is the energy supplemented by another system component to provide for the shortfall needed to meet design load completely. This energy could include supplementary thermal energy by electric or gas boiler. The average daily auxiliary energy is found from the positive value of Eq. (14). When Eq (14) results in negative value during the simulation, the negative values are taken as the system's excess thermal energy.

$Q_{\text {aux }}=\left[\int_{1}^{24} \dot{m}_{L} C_{p}\left(T_{L}-T_{\text {mains }}\right)-\int_{1}^{24} \dot{m}_{L} C_{p}\left(T_{d}-T_{\text {mains }}\right)\right]^{+}$

$T_{d}$ and $T_{\text {mains }}$ are the hot water temperatures delivered by the system and the mains water temperature. Another performance indicator that does not consider whether the collector's energy matches demand is system efficiency. Using this evaluator gives an idea of how well the system converts the total incident energy to hot water without concern for its usefulness. The system efficiency is defined as the ratio of the heat that changes the mains water temperature ( $\left.\mathrm{T}_{\text {mains }}\right)$ to the temperature at which water is delivered $\left(T_{L D T}\right)$ by the system load to the total energy received on the collector surface $\left(H_{T} A_{c}\right)$ as expressed in Eqn (15) (Ayompe and Duffy, 2013);

$\eta_{S}=\frac{\dot{m}_{L} C_{p}\left(T_{L D T}-T_{\text {mains }}\right)}{H_{T} A_{c}}$

Table 1

The design parameters and components sizes of the proposed solar hot water heating system

\begin{tabular}{|c|c|c|c|c|c|c|}
\hline & Component & TRNSY TYPE & Parameter & Value & unit & remark \\
\hline \multirow[t]{12}{*}{1} & $\begin{array}{l}\text { solar } \\
\text { collector }\end{array}$ & 565 & Absorber plate thickness & 3.18 & $\mathrm{~mm}$ & \\
\hline & & & Conductivity of absorber material & 220 & $\mathrm{~W} / \mathrm{m} \cdot \mathrm{K}$ & $\begin{array}{l}\text { Absorber plate } \\
\text { made from Al. }\end{array}$ \\
\hline & & & Serpentine Spacing & 0.1 & $\mathrm{~m}$ & \\
\hline & & & Serpentine Length & 1.0 & $\mathrm{~m}$ & \\
\hline & & & Inner tube diameter & 0.01 & $\mathrm{~m}$ & \\
\hline & & & Outer tube diameter & 0.012 & $\mathrm{~m}$ & \\
\hline & & & Absorptance absorber plate & 0.9 & - & \\
\hline & & & Emissivity of the Absorber Plate & 0.95 & - & $\begin{array}{c}\text { Emissivity of matt } \\
\text { black paint }\end{array}$ \\
\hline & & & Number of glass cover & 1.0 & - & \\
\hline & & & Collector tilt angle & 11.0 & Deg & $\begin{array}{l}\text { equal to the } \\
\text { latitude of the } \\
\text { location }\end{array}$ \\
\hline & & & Refractive index of glass & 1.53 & - & \\
\hline & & & Total Collector area & 2.541 & $\mathrm{~m}^{2}$ & $\begin{array}{l}\text { width }=1.1 \mathrm{~m} \\
\text { length }=2.3 \mathrm{~m}\end{array}$ \\
\hline \multirow[t]{4}{*}{2} & $\begin{array}{c}\text { Water } \\
\text { storage tank }\end{array}$ & 158 & Tank Volume (Laundry) & 0.15 & $\mathrm{~m}^{3}$ & $\begin{array}{l}\text { Equal to the daily } \\
\text { volume of hot } \\
\text { water demand }\end{array}$ \\
\hline & & & Tank height for all tanks & 1.20 & & \\
\hline & & & Tank Volume (post-natal) & 0.113 & $\mathrm{~m}^{3}$ & $\begin{array}{c}\text { Same reason as } \\
\text { above }\end{array}$ \\
\hline & & & Tank 3 (Sterilisation) & 0.088 & $\mathrm{~m}^{3}$ & $\begin{array}{c}\text { Same reason as } \\
\text { above }\end{array}$ \\
\hline \multirow[t]{2}{*}{3} & solar pump & 110 & Rated flow rate & 0.02 & $\mathrm{~kg} / \mathrm{s}$ & $\begin{array}{l}\text { As recommended } \\
\text { in most studies }\end{array}$ \\
\hline & & & Power consumption & 64 & watt & \\
\hline
\end{tabular}




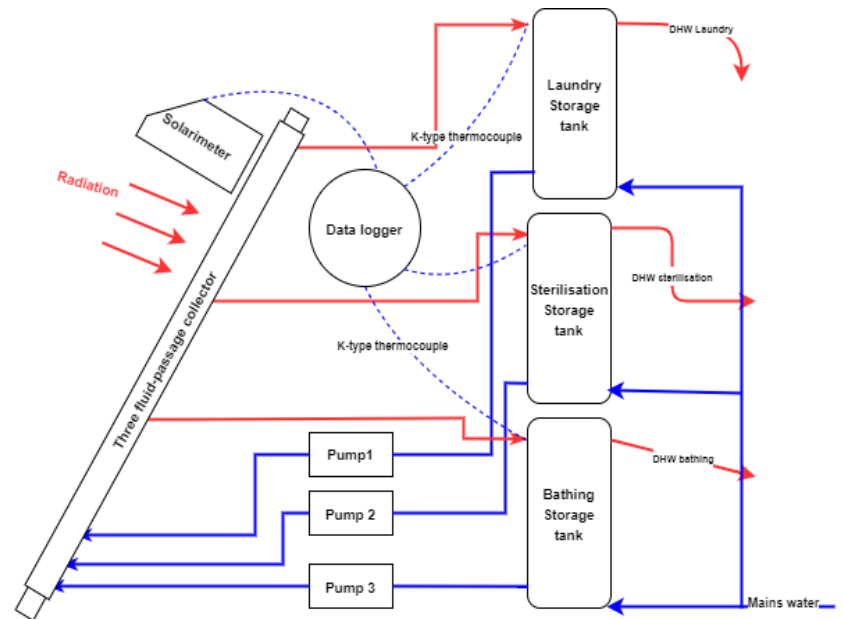

Fig 5. View of the outdoor experimental setup of the proposed 3loop solar water heating system

\subsection{Experimental validation of system model}

To compare the system's predicted performance, the simulated system was built. The outdoor performance of the system was experimentally measured at Abubakar Tafawa Balewa University Bauchi, Nigeria. Figure 5 shows the developed system and experimental setup used to measure the system's outdoor performance. The water temperature in the storage tank was the selected parameter for validation. This parameter is crucial to both the designer and the end-user (Yanto et al., 2017).

The performance was measured one day in January and August. These months are selected because they represent months with good solar and poor solar radiation, respectively. Each day experiment was started from 8:00 hours to 18:00 hours. During the experiment, the threetank outlet and inlet temperatures were measured at an interval of one hour using, a K-type thermocouple wire connected to a digital reader. The flow rate through the collector was taken as the pump's flow rate since the pump is operated at a constant flow rate of $72 \mathrm{~kg} / \mathrm{hr}$ during the test period. The solar irradiance received on the collector's surface was also measured using the digital pyrometer with an accuracy of $+/-50$ watts. The hourly measurement of the temperatures obtained during the experiment was recorded for laundry, sterilisation and postnatal services. These results were analysed using the statistical tool to determine the validity of the model formulated using TRNSYS. The coefficient of variation of the root-meansquare error, $\mathrm{Cv}(\mathrm{RMSE})$ and Nash-Sutcliffe coefficient of efficiency (NSE) given by Eqn. (16) and (17) (Yanto et al., 2017) (Teixeira et al., 2020) were adopted to compare to measure the relative error between the predicted temperature and measured temperature. The confidence level of the model was assessed based on NSE Eqn. (19). ;

$\mathrm{Cv}(\mathrm{RMSE})=\sqrt{\frac{\sum_{i=1}^{n}\left(X_{\text {sim }, i}-X_{\text {expt }, i}\right)^{2}}{n}} \times \frac{100}{\bar{X}_{\text {expti }}}$

$N S E=1-\frac{\sum_{i=1}^{n}\left(X_{\text {expt }, i}-X_{\text {Sim }, i}\right)^{2}}{\sum_{i=1}^{n}\left(X_{\text {expt }, i}-\bar{X}_{\text {expti }}\right)^{2}}$ where $\mathrm{X}_{\text {sim }}$ is the simulated parameter, $\mathrm{X}_{\text {expt }}$ is the measured parameter and $\bar{X}_{\text {expt }}$ is the experimental mean of the measured variable.

\section{Results and Discussions}

\subsection{Analysis of system load}

The weather condition, which significantly influences solar system design varies randomly with time for every location (Brownson, 2014). As a result, solar energy system performance equally, varies significantly with time and locations. Therefore, assessing the solar energy system's performance on a monthly average daily basis is considered a reasonable approximation and fair assessment of system performance. Figure 6 shows the monthly average daily thermal load demand for each application. The thermal demand for laundry, sterilisation, and postnatal services are significantly different due to the difference in volume and temperature required for each hot water application. Notably, while the volume $(88 \mathrm{~L})$ of hot water demand for sterilisation is lower than that needed for postnatal services, the thermal demand for sterilisation is approximately $20 \%$ higher than that required for postnatal services. This difference again shows that the temperature at which the hot water is required is crucial in determining the energy requirement. In this case, a difference of about $20 \%$ signifies a potential reduction of the collector's total thermal energy production to meet hot water demand if separate hot water tanks are employed.

The implication of employing a single hot water tank in the solar system for hot water demand at different temperature and volume is that the water is mixed. Consequently, to satisfactorily meet hot water demand at $43^{\circ} \mathrm{C}, 54^{\circ} \mathrm{C}$ and $60^{\circ} \mathrm{C}$ as in this study, the water must be heated to a temperature of $60^{\circ} \mathrm{C}$. In this case, the collector size required will be much higher than necessary. Besides, for hot water required at different temperatures, meeting the demand at a higher temperature may result in excess thermal energy dumped.

In this case, the hot water requirement for sterilisation is 88 litres. Postnatal and laundry services require 113 litres and 150 litres, respectively. The overall demand in this health centre for hot water, therefore, stands at 351 litres. As mentioned earlier, the demands for the separate services are separated into three different tanks. Therefore, based on the established equations in section 2 of this study, the thermal energy required to increase each tank's temperature to the desired temperature is calculated and summed to obtain the total thermal energy demand. the total energy is compared to that required if the hot water demand for each application is combined in a single tank and then heated to the maximum temperature demand of $60^{\circ} \mathrm{C}$. Figure 7 compares the total energy demand for separate hot water tanks and the single hot water tank. It was observed that the total thermal energy demand for heating the total volume of hot water to $60^{\circ} \mathrm{C}$ in a single tank is significantly higher by about $27 \%$ than that required to meet the demand for the various applications if the hot water demand is separated and meet separately. The drawback of sizing the solar water heating system to meet hot water demand based on the single storage tank, as demonstrated in this study is the production of excess thermal energy. 
This excess energy is mostly dumped since it cannot be stored.

\subsection{Collector efficiency and characterisation}

The system temperature behaviour recorded during the outdoor experiment on a clear day is processed to characterise the proposed "three fluid-passage" serpentine collector, as shown in Figure 8. From the equation of the line of best fit, the slope of the efficiency curve was found to be $6.1 \mathrm{~W} / \mathrm{m}^{2} \mathrm{~K}$. The slope of the efficiency curve is equal to the collector heat removal- loss efficient product $\left(F_{R} U_{L}\right)$ and the intercept of the line on the efficiency axis is the heat removal factor-transmittance absorptance product $\left(F_{R} \tau \alpha\right)$ equal to 0.71 . The collector's efficiency in this study is zero at a temperature difference of 0.12 and similarly zero at a temperature difference of 0.15 the review conducted by Akram (Akram et al., 2020).

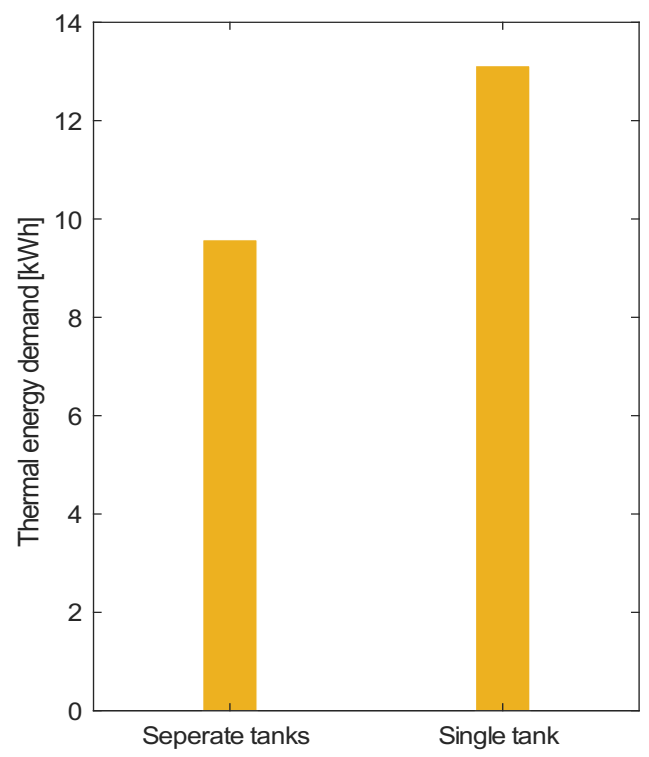

Fig 7. Total a hot water demand for separated tanks and single tank.

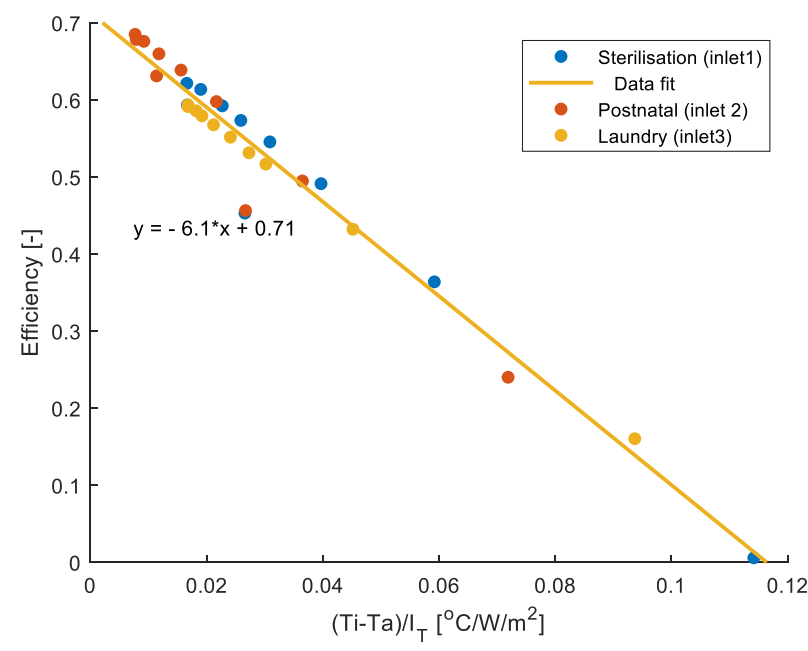

Fig 8:. Efficiency curve of the proposed collector.

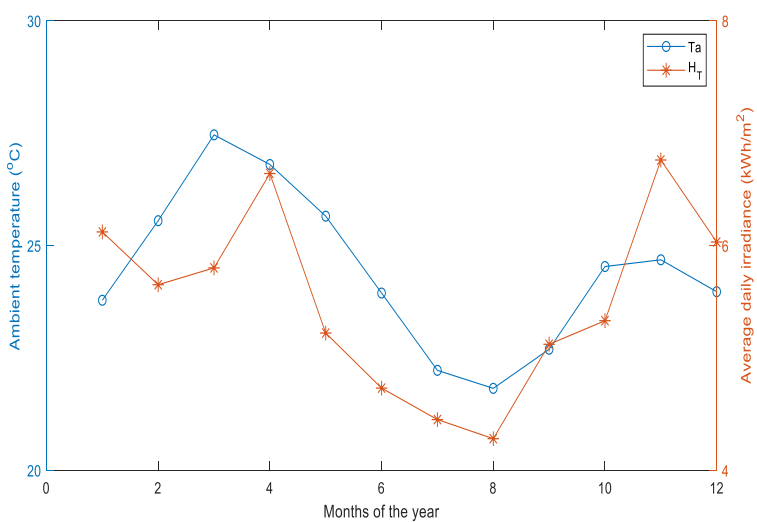

Fig 10. Monthly average daily solar irradiance and ambient temperature of Bauchi, Nigeria

Similarly, Figures 9 and 10 compare the proposed collector's simulated collector efficiency to the conventional serpentine collector based on the same design and operational parameters on a clear sky day and cloudy sky day, respectively. From both figures, it is seen that for both sunny and cloudy days, the proposed collector configuration shows significantly higher collector efficiency than the conventional collector. This trend is due to the fact that the water coming into the collector is entering a low temperature since, for postnatal applications, the water is recirculated in the collector at a lower temperature $\left(43^{\circ} \mathrm{C}\right)$.
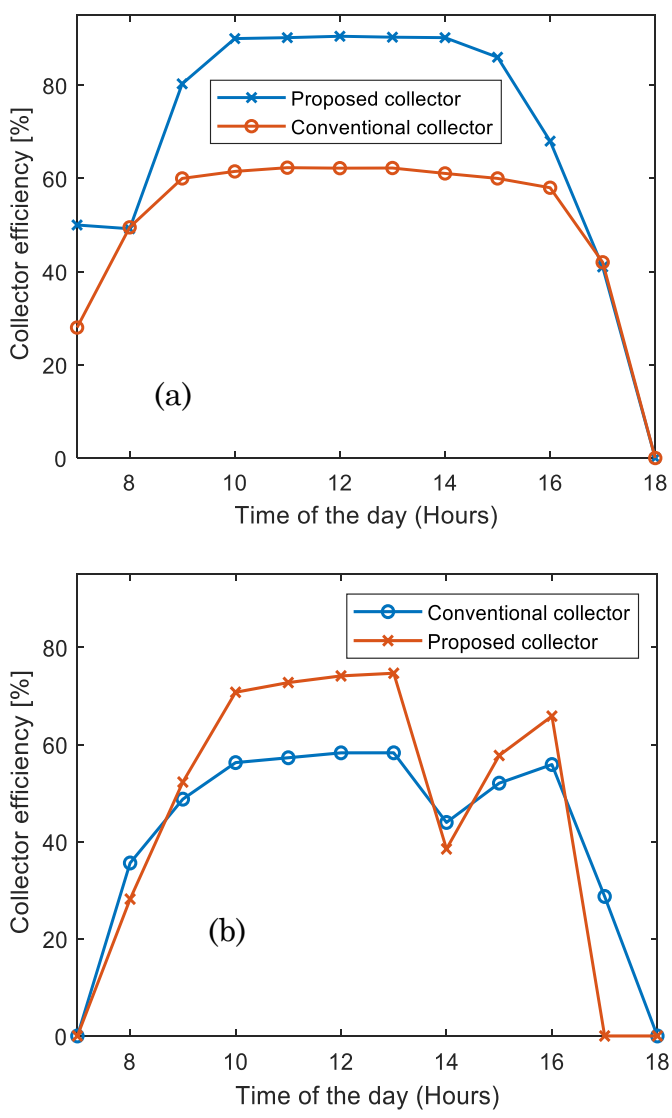

Fig 9. Collector efficiency of conventional and proposed on (a) cloudy day and (b) cloudy day 
Hence, in this way, there is better extraction of heat by the circulated water compare to the single inlet collector operated base on a single hot water storage tank. Thus, the energy conversion rate to useful thermal energy in this study is about $30 \%$ and $20 \%$ higher in the proposed collector than the conventional serpentine collector on both sunny and cloudy days respectively as observed in Figures 9.

\subsection{Monthly average temperature of hot water delivered}

Comparing the monthly averaged daily hot water delivered for the three applications, Figure 9 shows that the hot water temperature delivered by the system for postnatal service is above the required temperature in most of the months. As seen in Figure 9, these performances reflect the solar radiation availability in each month. For this study, solar radiation is higher from January to May and September to December, as shown in Figure 10. June to August shows a lower level of solar radiation; hence system performance is lower in these months, as seen in Figures 9. Significantly, the auxiliary energy requirement is divided when loads are separated, allowing for just the energy required in each application to be supplied.

\subsection{System thermal performance analysis}

The solar fraction, which is the portion of the load met using a solar energy system, is a critical indicator to assess the solar system's overall performance. The solar fraction is a performance matrix that measures the entire system performance rather than the component performance. It is, in other words, it a performance matrix that reveals the system capacity to meet the hot water demand at the desired temperature. Figure 12 compares the system's monthly average daily solar fraction based on the triinlet/outlet collector and the conventional serpentine collector. Overall, the system's solar fraction based on the proposed collector configuration and system architecture is observed to be higher in all months than that based on the conventional serpentine collector and system architecture. As seen from Figure 13 the average daily useful energy (solar fraction) based on the proposed designed is about $83.5 \%$ indicating an improvement of about $11.6 \%$ in a solar fraction when compared to the convention system architecture which has a solar fraction of $71.9 \%$

A detailed thermal assessment of the three tanks' hot water for the different applications indicates that the hot water is delivered at a higher temperature at sometimes, as seen in Figures 11. This elevated temperature consequently produces the excess thermal energy. Unfortunately, excess thermal energy in a solar water heating system that is not used immediately has no economic value. Therefore, oversizing to produce excess thermal energy has no economic value. While excess thermal energy of about $3.6 \%$ and $18.25 \%$ was supplied by both the proposed system and conventional system architecture, approximately $28 \%$ and $16 \%$ of auxiliary energy still must be supplied to meet all thermal needs reliability. Hence, suggesting that the excess thermal energy is merely due to load mismatch.

Overall, the proposed collector configuration and system architecture have shown higher solar fraction capacity, reducing the extra needed energy by about $12 \%$. This extra energy reduction has further shown that the system's carbon dioxide mitigation impact is further enhanced by the proposed system designed and collector configuration. Finally, a solar fraction of $67 \%$ for the month with the worst solar radiation as shown in Figure 12 shows that the collector's size is within the limit, as recommended by the National Renewable Laboratory (NREL) guideline for the design of solar water heating system (National Renewable Laboratory NREL, 2015).
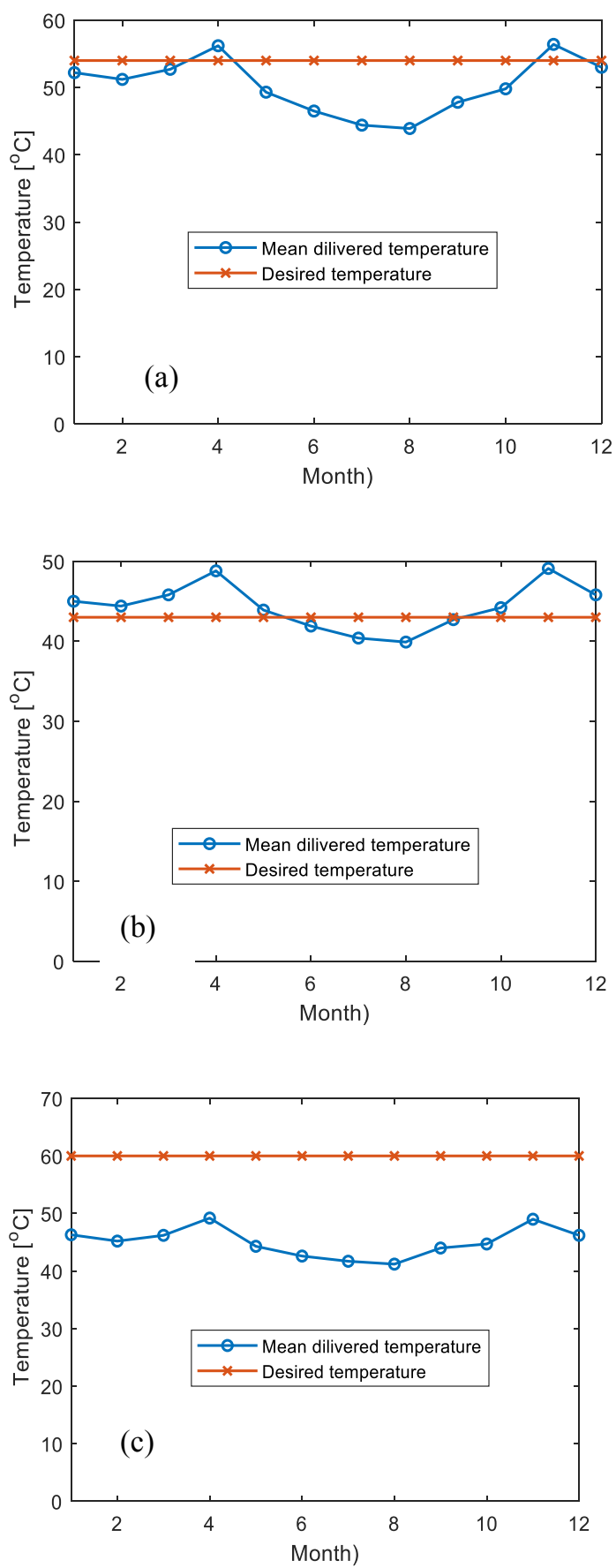

Fig 11. Monthly average water temperature delivered for (a) laundry (b) postnatal (c) sterilisation services, based on the proposed collector 


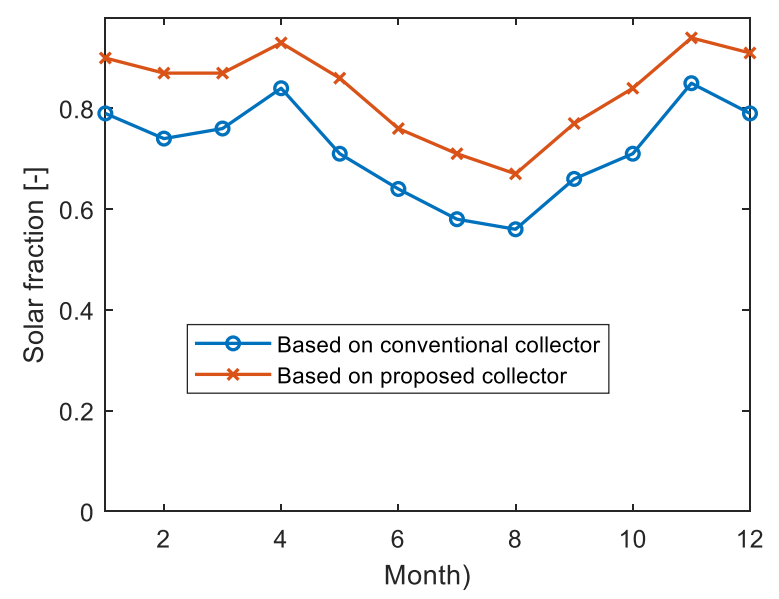

Fig 12. Solar system fraction based on the conventional and the proposed collector

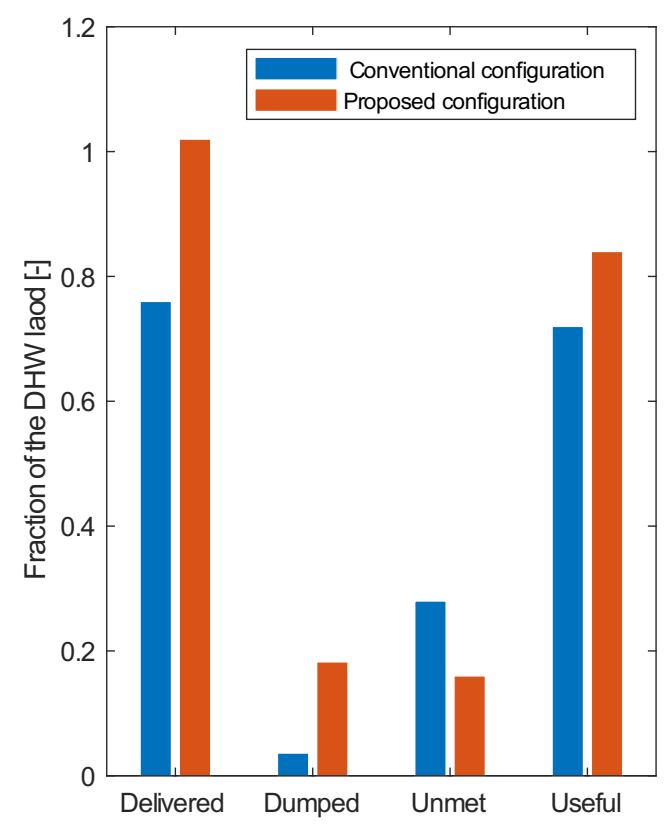

Fig 13. Performance of the proposed system in comparison to the typical serpentine system

\subsection{Experimental validation of simulated results}

Figures 14 and 18 compare the simulated tank outlet temperature with the measure tank outlet temperature for postnatal (a) and laundry (b) on the $4^{\text {th }}$ of January and August. January represents the system performance on the day with a high level of solar radiation and clear sky. Similarly, August stands for the system's performance daily with low radiation and cloudy sky level. Table 2 shows the Nash-Sutcliffe coefficient of efficiency (NSE) between the measured and the predicted tank outlet temperature. NSE is a matrix used to evaluate how close, the formulated model represents the entire system. It is observed that the measured temperatures in all the tanks show close agreement with the simulated tank outlet temperatures. As observed from Table 2, a lower
CV(RMSE) value does not imply better agreement of measured value to the simulated result. Particularly in August, the simulated laundry tank outlet temperature is observed to have a $\mathrm{Cv}(\mathrm{RMSE})$ value of $11.7 \%$. However, it has a confidence level (NSE) of $77.6 \%$ compared to a $\mathrm{Cv}$ (RMSE) value of $8.56 \%$ with a lower NSE of $67.2 \%$ as observed with the postnatal tank temperature in August.

Overall, the average percentage error $\mathrm{Cv}(\mathrm{RMSE})$ of 8.67\% and confidence level NSE of $87.6 .1 \%$ shown in Table 2 exceed the minimal accepted values of the plus or minus $30 \%$ and $60 \%$ respectively (Teixeira et al., 2020).

Table 2

Error analysis of measured and simulated system performance

\begin{tabular}{cccc}
\hline Month & $\begin{array}{c}\text { Service tank } \\
\text { outlet } \\
\text { temperature }\end{array}$ & Cv(RMSE)\% & NSE[-] \\
\hline Jan & Laundry & 9.379 & 0.905 \\
& Postnatal & 5.184 & 0.969 \\
Aug & Sterilisation & 11.89 & 0.917 \\
& Laundry & 11.02 & 0.776 \\
& Postnatal & 8.56 & 0.671 \\
& Sterilisation & 6.466 & 0.952 \\
& Sys. Aver & 8.75 & 0.87 \\
\hline
\end{tabular}
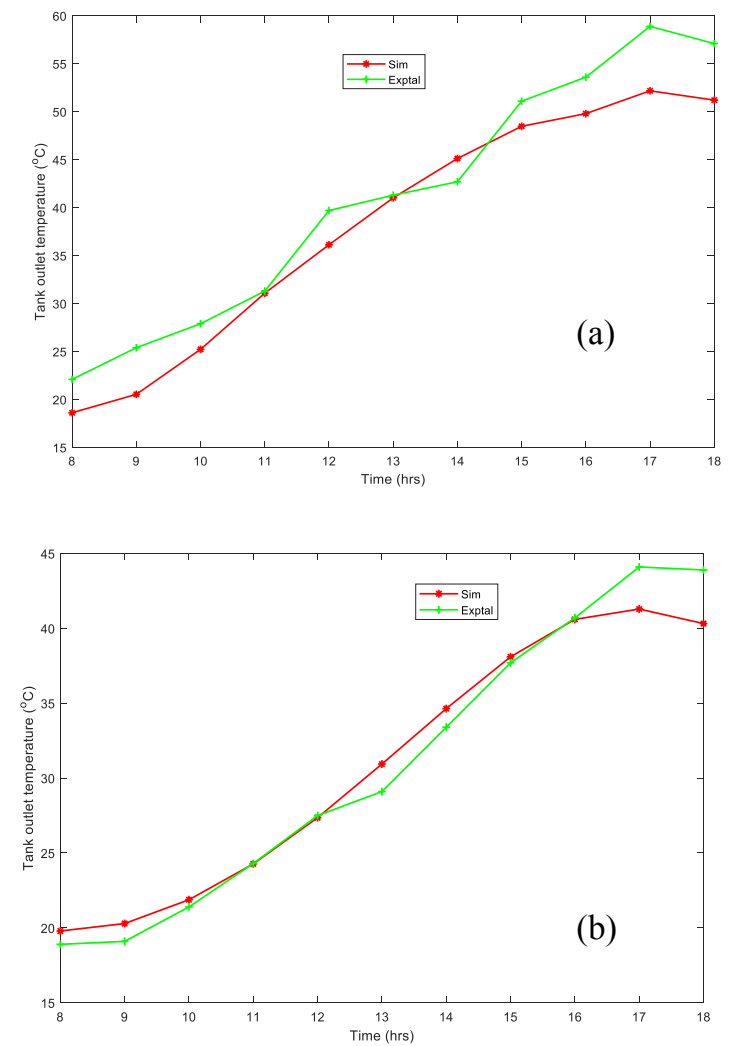

Fig 14. Comparison of simulated and measured tank outlet water temperature for (a) laundry and (b) Postnatal services tank on $4 / 01 / 2017$ 

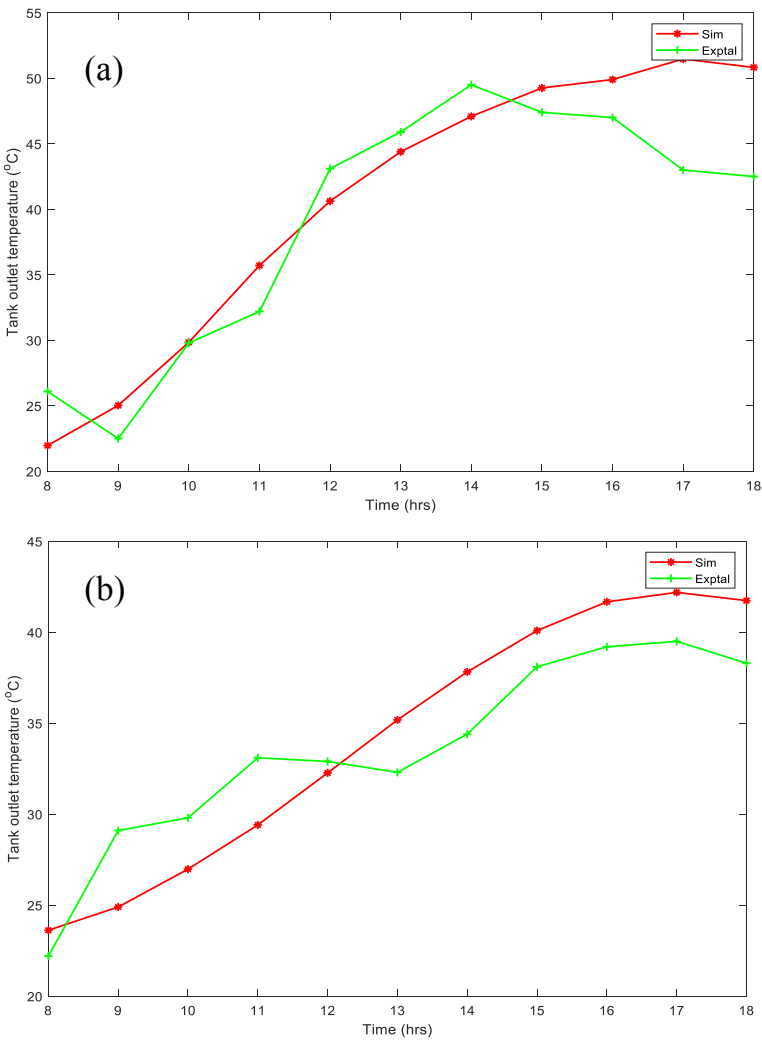

Fig 15. Comparison of simulated and measured tank outlet water temperature for (a) laundry and (b) Postnatal services tank on $4 / 08 / 2017$

\section{Conclusion}

In this study, a novel serpentine, flat plate collector with three in-line copper fluid passages is proposed. The aim is to design a single collector that can supply hot water at different temperatures for sterilisation, laundry and postnatal services in small health centres. The study compares the system's performance based on the novel serpentine collector configuration to system performance based on the typical serpentine collector configuration to determine the proposed collector's advantage over the typical one. From the results of this study, the following conclusions are drawn. The three hospital hot water services' thermal requirement was significantly reduced by about $27 \%$ when the hot water demand for these services is provided employing three separate tanks. Moreover, the serpentine collector efficiency based on the proposed three in-line fluid passages is improved by about $20 \%$ relative to the conventional serpentine collector. Consequently, the average daily energy delivered to load based on the proposed collector configuration and system architecture is about $30 \%$ higher than that of the conventional serpentine system configuration.

Overall, the experimental system performance and the simulated system performance is in close agreement with an average percentage error $\mathrm{Cv}(\mathrm{RMSE})$ of $8.75 \%$ and confidence level NSE of about $87 \%$. Therefore, the model formulated is a good representative of the existing system.The proposed serpentine collector configuration's thermal production is significantly higher than that of the conventional serpentine configuration. Hence, the proposed serpentine collector configuration is recommended for hot water applications where demand is required at various temperatures and volumes. The second question is whether the study's proposed design is economically more effective than conventional serpentine collector design. Accordingly, in the future study, a feasibility study may be recommended to compare the proposed design with the traditional serpentine collector system.

\section{Acknowledgments}

We wish to acknowledge the technical staff of Abubakar Tafawa Balewa University Bauchi, Nigeria who constructed the system and recorded the experimental readings throughout one year.

\section{References}

Ahmadi, M. H., Baghban, A., Sadeghzadeh, M., Zamen, M., Mosavi, A., Shamshirband, S., ... MohammadiKhanaposhtani, M. (2020). Evaluation of electrical efficiency of photovoltaic thermal solar collector. Engineering Applications of Computational Fluid Mechanics, 14(1), 545-565. https://doi.org/10.1080/19942060.2020.1734094

Ahmadi, M. H., Ghazvini, M., Sadeghzadeh, M., Alhuyi Nazari, M., Kumar, R., Naeimi, A., \& Ming, T. (2018). Solar power technology for electricity generation: A critical review. Energy Science and Engineering, 6(5), 340-361. https://doi.org/10.1002/ese3.239

Akram, N., Sadri, R., Kazi, S. N., Zubir, M. N. M., Ridha, M., Ahmed, W., ... Arzpeyma, M. (2020). A comprehensive review on nanofluid operated solar flat plate collectors. Journal of Thermal Analysis and Calorimetry, 139(2), 1309-1343. https://doi.org/10.1007/s10973-019-08514-z

Ayompe, L. M., \& Duffy, A. (2013). Analysis of the thermal performance of a solar water heating system with flat plate collectors in a temperate climate. Applied Thermal Engineering, 58(1-2), 447-454. https://doi.org/10.1016/j.applthermaleng.2013.04.062

Backer, H. D. (1996). Effect of Heat on the Sterilization of Artificially Contaminated Water. Journal of Travel Medicine, 3, 1-4. Retrieved from https://academic.oup.com/jtm/article/3/1/1/1804390

Beausoleil-Morrison, I., Kemery, B., Wills, A. D., \& Meister, C. (2019). Design and simulated performance of a solarthermal system employing seasonal storage for providing the majority of space heating and domestic hot water heating needs to a single-family house in a cold climate. Solar Energy, 191(May), 57-69. https://doi.org/10.1016/j.solener.2019.08.034

Braun, R., Haag, M., Stave, J., Abdelnour, N., \& Eicker, U. (2020). System design and feasibility of trigeneration systems with hybrid photovoltaic-thermal (PVT) collectors for zero energy office buildings in different climates. Solar Energy, 196(September 2019), 39-48. https://doi.org/10.1016/j.solener.2019.12.005

Brownson, J. R. S. (2014). Solar Energy Conversion Systems (First edit; Elsevier, ed.). Waltham, USA: Academic Press imprint of Elsevier.

Bujak, J. (2010). Heat consumption for preparing domestic hot water in hospitals. Energy and Buildings, 42(7), 10471055. https://doi.org/10.1016/j.enbuild.2010.01.017

Costa, L., \& Bracco, P. (2009). Mechanisms of Crosslinking, Oxidative Degradation and Stabilization of UHMWPE. In UHMWPE Biomaterials Handbook (pp. 309-323). https://doi.org/10.1016/B978-0-12-374721-1.00021-3

Deng, J., O'Donovan, T. S., Tian, Z., King, J., \& Speake, S. (2019). 
Thermal performance predictions and tests of a novel type of flat plate solar thermal collectors by integrating with a freeze tolerance solution. Energy Conversion and Management, https://doi.org/10.1016/j.enconman.2019.111784

Diez, F. J., Navas-Gracia, L. M., Martínez-Rodríguez, A., CorreaGuimaraes, A., \& Chico-Santamarta, L. (2019). Modelling of a flat-plate solar collector using artificial neural networks for different working fluid (water) flow rates. Solar Energy, 188, 1320-1331. https://doi.org/10.1016/j.solener.2019.07.022

Dubey, S., Sarvaiya, J. N., \& Seshadri, B. (2013). Temperature dependent photovoltaic (PV) efficiency and its effect on PV production in the world - A review. Energy Procedia, 33, 311-321. https://doi.org/10.1016/j.egypro.2013.05.072

Duffie, J. . A., \& Beckman, W. A. (2013). Solar Engineering of Thermal Processes (Fourth). Retrieved from https://www.sku.ac.ir/Datafiles/BookLibrary/45/John A. Duffie, William A. Beckman(auth.)-Solar Engineering of Thermal Processes, Fourth Edition (2013).pdf

Eltaweel, M., Abdel-Rehim, A. A., \& Hussien, H. (2020). Indirect thermosiphon flat-plate solar collector performance based on twisted tube design heat exchanger filled with nanofluid. International Journal of Energy Research, 44(6), 42694278. https://doi.org/10.1002/er.5146

Fawaz, H. E., Badawy, M. T. S., Abd Rabbo, M. F., \& Elfeky, A. (2018). Numerical investigation of fully developed periodic turbulent flow in a square channel fitted with $45^{\circ}$ in-line $\mathrm{V}$ baffle turbulators pointing upstream. Alexandria Engineering Journal, 57(2), 633-642. https://doi.org/10.1016/j.aej.2017.02.020

Fertahi, S. ed D., Jamil, A., Kousksou, T., \& Benbassou, A. (2019). Energy performance enhancement of a collective hot water production process equipped with a centralized storage tank. Journal of Energy Storage, 25, 100849. https://doi.org/10.1016/j.est.2019.100849

Fuentes, E., Arce, L., \& Salom, J. (2018). A review of domestic hot water consumption profiles for application in systems and buildings energy performance analysis. Renewable and Sustainable Energy Reviews, 81(February), 1530-1547. https://doi.org/10.1016/j.rser.2017.05.229

Govind N. K, Shireesh B. K, S. B. (2006). Determination of design space and optimization of solar water heating systems. Solar Energy, 32, 263-276.

Honisch, M., Stamminger, R., \& Bockmühl, D. P. (2014). Impact of wash cycle time, temperature and detergent formulation on the hygiene effectiveness of domestic laundering. Journal of Applied Microbiology, 117(6), 1787-1797. https://doi.org/10.1111/jam.12647

Hoseinzadeh, S., \& Azadi, R. (2017). Simulation and optimization of a solar-assisted heating and cooling system for a house in Northern of Iran. Journal of Renewable and Sustainable Energy, 9(4). https://doi.org/10.1063/1.5000288

Hoseinzadeh, S., Ghasemi, M. H., \& Heyns, S. (2020). Application of hybrid systems in solution of low power generation at hot seasons for micro hydro systems. Renewable Energy, 160, 323-332. https://doi.org/10.1016/j.renene.2020.06.149

Hossain, M. S., Pandey, A. K., Tunio, M. A., Selvaraj, J., Hoque, K. E., \& Rahim, N. A. (2016). Thermal and economic analysis of low-cost modified flat-plate solar water heater with parallel two-side serpentine flow. Journal of Thermal Analysis and Calorimetry, 123(1), 793-806. https://doi.org/10.1007/s10973-015-4883-7

Kalogirou, S. (2009). Solar energy engineering: processes and systems. In Academic Press publications. https://doi.org/10.1016/B978-0-12-374501-9.00014-5

Kiliç, F., Menlik, T., \& Sözen, A. (2018). Effect of titanium dioxide/water nanofluid use on thermal performance of the flat plate solar collector. Solar Energy, 164(April 2017), 101-108. https://doi.org/10.1016/j.solener.2018.02.002

Li, W. T., Tushar, W., Yuen, C., Ng, B. K. K., Tai, S., \& Chew, K. T. (2020). Energy efficiency improvement of solar water heating systems - An IoT based commissioning methodology. Energy and Buildings, 224, 110231. https://doi.org/10.1016/j.enbuild.2020.110231

Lima, T. P., Dutra, J. C. C., Primo, A. R. M., Rohatgi, J., \& Ochoa, A. A. V. (2015). Solar water heating for a hospital laundry: A case study. Solar Energy, 122, 737-748. https://doi.org/10.1016/j.solener.2015.10.006

Madvar, M. D., Nazari, M. A., Arjmand, J. T., Aslani, A., Ghasempour, R., \& Ahmadi, M. H. (2018). Analysis of stakeholder roles and thechallenges of solar energy utilization in Iran. International Journal of Low-Carbon Technologies, 13(4), 438-451. https://doi.org/https://doi.org/10.1093/ijlct/cty044

Memon, S., Katsura, T., Radwan, A., Zhang, S., Serageldin, A. A., Abo-Zahhad, E. M., ... Kiani, A. (2020). Modern Eminence and Concise Critique of Solar Thermal Energy and Vacuum Insulation Technologies for Sustainable Low-Carbon Infrastructure. International Journal of Solar Thermal Vacuum Engineering, 1(1), 52-71. https://doi.org/10.37934/stve.1.1.5271

Menni, Y., Azzi, A., \& Chamkha, A. (2019, February 28). Enhancement of convective heat transfer in smooth air channels with wall-mounted obstacles in the flow path: A review. Journal of Thermal Analysis and Calorimetry, Vol. 135, pp. 1951-1976. https://doi.org/10.1007/s10973-0187268-x

Murphy, P. A. (1993, January 1). A guide to effective care in pregnancy and childbirth. Edited by Murray Enkin, Marc J.N.C. Keirse, and Iain Chalmers. New York: Oxford University Press, 1990. 376 pages. \$24.95, softcover. Journal of Nurse-Midwifery, Vol. 38, pp. 58-60. https://doi.org/10.1016/0091-2182(93)90137-6

National Renewable Laboratory NREL. (2015). High Performance Flat Plate Solar Thermal Collector Evaluation. Retrieved from https://www.nrel.gov/docs/fy16osti/66215.pdf

Ohijeagbon, O. D., Ajayi, O., Waheed, O., Adekojo, M., Salawu, E. Y., \& Oyawale, F. A. (2019). Design of optimal hybrid renewable energy system for sustainable power supply to isolated-grid communities in North Central, Nigeria. Procedia Manufacturing, 35, 278-284. https://doi.org/10.1016/j.promfg.2019.05.040

Olatomiwa, L. (2016). Optimal configuration assessments of hybrid renewable power supply for rural healthcare facilities. Energy Reports, 2, 141-146. https://doi.org/10.1016/j.egyr.2016.06.001

Olatomiwa, L., Mekhilef, S., \& Ohunakin, O. S. (2016). Hybrid renewable power supply for rural health clinics ( $R H C$ ) in six geo-political zones of Nigeria. 13, 1-12. https://doi.org/10.1016/j.seta.2015.11.001

Rejeb, O., Gaillard, L., Giroux-Julien, S., Ghenai, C., Jemni, A., Bettayeb, M., \& Menezo, C. (2020). Novel solar PV/Thermal collector design for the enhancement of thermal and electrical performances. Renewable Energy, 146, 610-627. https://doi.org/10.1016/j.renene.2019.06.158

Rosli, M. A. M., Misha, S., Sopian, K., Mat, S., Yusof Sulaiman, M., \& Salleh, E. (2014). Parametric analysis on heat removal factor for a flat plate solar collector of serpentine tube. World Applied Sciences Journal, 29(2), 184-187. https://doi.org/10.5829/idosi.wasj.2014.29.02.1357

Shariah, A.M and Shialabi, B. (2013). Optimal Design for a Thermosyphon Solar Flat Plate Water Heater. Renewable Energy, 11((12), $351-361$.

Sohani, A., Hoseinzadeh, S., \& Berenjkar, K. (2020). Experimental analysis of innovative designs for solar still desalination technologies; An in-depth technical and economic assessment. Journal of Energy Storage, (May), 101862. https://doi.org/10.1016/j.est.2020.101862

Sukhatme, S. (2009). Solar Energy: Principles of Thermal Collection and Storage. India: Tata McGraw-hill Publishing Company.

Teixeira, H., Gomes, M. G., Moret Rodrigues, A., \& Pereira, J. (2020). Thermal and visual comfort, energy use and 
environmental performance of glazing systems with solar control films. Building and Environment, 168, 106474. https://doi.org/10.1016/j.buildenv.2019.106474

World Energy Council. (2004). 2004 Survey of Energy Resources. In Judy Trinnaman and Alan Clarke (Ed.), Solar Energy (Twentieth, pp. 295-334). Elsevier Science \& Technology Books.

Yanto, Livneh, B., Rajagopalan, B., \& Kasprzyk, J. (2017). Hydrological model application under data scarcity for multiple watersheds, Java Island, Indonesia. Journal of Hydrology: Regional Studies, 9, 127-139. https://doi.org/10.1016/j.ejrh.2016.09.007
Yousef Nezhad, M. E., \& Hoseinzadeh, S. (2017). Mathematical modelling and simulation of a solar water heater for an aviculture unit using MATLAB/SIMULINK. Journal of Renewable and Sustainable Energy, 9(6). https://doi.org/10.1063/1.5010828

Zulkifle, I., Alwaeli, A. H. A., Ruslan, M. H., Ibarahim, Z., Othman, M. Y. H., \& Sopian, K. (2018). Numerical investigation of V-groove air-collector performance with changing cover in Bangi, Malaysia. Case Studies in Thermal Engineering, 12, 587-599. https://doi.org/10.1016/j.csite.2018.07.012 